\title{
Contrails, Natural Clouds, and Diurnal Temperature Range
}

\author{
Simone Dietmüller, Michael Ponater, Robert Sausen, and Klaus-Peter Hoinka \\ Institut für Physik der Atmosphäre, Deutsches Zentrum für Luft- und Raumfahrt, Oberpfaffenhofen, Germany \\ SusAnNe PeChTL* \\ Institut für Umweltphysik der Universität Heidelberg, Heidelberg, Germany
}

(Manuscript received 24 September 2007, in final form 7 March 2008)

\begin{abstract}
The direct impact of aircraft condensation trails (contrails) on surface temperature in regions of high aircraft density has been a matter of recent debate in climate research. Based on data analysis for the 3-day aviation grounding period over the United States, following the terrorists' attack of 11 September 2001, a strong effect of contrails reducing the surface diurnal temperature range (DTR) has been suggested. Simulations with the global climate model ECHAM4 (including a contrail parameterization) and long-term time series of observation-based data are used for an independent cross check with longer data records, which allow statistically more reliable conclusions. The climate model underestimates the overall magnitude of the DTR compared to 40-yr ECMWF Re-Analysis (ERA-40) data and station data, but it captures most features of the DTR global distribution and the correlation between DTR and either cloud amount or cloud forcing. The diurnal cycle of contrail radiative impact is also qualitatively consistent with expectations, both at the surface and at the top of the atmosphere. Nevertheless, there is no DTR response to contrails in a simulation that inhibits a global radiative forcing considerably exceeding the upper limit of contrail radiative impact according to current assessments. Long-term trends of DTR, the level of natural DTR variability, and the specific effect of high clouds on DTR are also analyzed. In both ECHAM4 and ERA-40 data, the correlation of cloud coverage or cloud radiative forcing with the DTR is mainly apparent for low clouds. None of the results herein indicates a significant impact of contrails on reducing the DTR. Hence, it is concluded that the respective hypothesis as derived from the 3-day aviation-free period over the United States lacks the required statistical backing.
\end{abstract}

\section{Introduction}

According to available assessment studies, aircraft condensation trails form a significant contribution to total aviation climate impact (Penner et al. 1999; Sausen et al. 2005). Estimates of the global radiative forcing of line-shaped contrails vary from 17.5 (Minnis et al. 1999) down to $2.0 \mathrm{~mW} \mathrm{~m}^{-2}$ (Stuber and Forster 2007) for 1992 aviation, with most of the uncertainty being attributed to a lack of detailed knowledge on contrail optical properties. For example, contrail optical depth

* Current affiliation: Deutsches Patent- und Markenamt, $\mathrm{Mu}-$ nich, Germany.

Corresponding author address: Simone Dietmüller, DLRInstitut für Physik der Atmosphäre, Oberpfaffenhofen, D-82230 Wessling, Germany.

E-mail: simone.dietmueller@dlr.de may take a wide range of values over various seasons, geographical regions, and altitudes (Marquart et al. 2003; Palikonda et al. 2005), which renders the determination of something like a typical or mean value quite difficult. The coverage of line-shaped contrails can be better constrained from observations (e.g., Meyer et al. 2002; Palikonda et al. 2005; Meyer et al. 2007), so that estimates for its global mean value vary by hardly more than a factor 2 . However, the coverage of all aviation-induced cirrus (AIC) is probably higher, possibly much more so, than its line-shaped component (e.g., Zerefos et al. 2003; Minnis et al. 2004). The difficulty in identifying the naturally looking but nevertheless aircraft-induced part of total high cloudiness from satellite images (Mannstein and Schumann 2005, 2007) and the absence of sufficiently advanced climate model studies has thus far prevented the calculation of a radiative forcing best estimate for AIC as a whole (Sausen et al. 2005). 
There have been attempts to estimate the impact of AIC through parameters other than radiative forcing. Minnis et al. (2004) used empirical models to derive a trend of mean temperature from observed cirrus trends over the continental United States, putting forth the hypothesis that all observed warming over this area between 1975 and 2004 could possibly be explained by aviation increase. However, it was demonstrated by Shine (2005) that the trend attribution proposed in Minnis et al. (2004) was impossible to reconcile with existing knowledge about contrail radiative forcing and current theories about the relation between regional radiative forcing and the geographical distribution of a long-term surface temperature response (e.g., Boer and Yu 2003). Although Minnis (2005) insisted that the current forcing and response theory might only account for large-scale equilibrium effects, while AIC would force an additional local effect, it seems almost certain that the contrail forcing is not acting in a completely different way than more conventional forcing agents. A GCM study by Ponater et al. (2005), in which the largescale, as well as the instantaneous, local response of AIC forcing was included by means of a contrail parameterization scheme, fully confirmed the conclusions drawn by Shine (2005) that the regional response to AIC was overestimated in Minnis et al. (2004) by at least an order of magnitude.

In this article we will extend the analysis of the contrail climate sensitivity simulations discussed by Ponater et al. (2005) to the diurnal range of surface temperature. The diurnal temperature range (DTR) is an important climate parameter because of its specific impact on various biosphere features (e.g., Lobell et al. 2006). Travis et al. $(2002,2004)$ put forth the hypothesis of the substantial influence of contrails (or in fact, of AIC) in reducing DTR. They found a rather large DTR increase during the grounding period of commercial aircraft over the United States, following the terrorists' attack on 11 September 2001. Comparing observations during the 3-day period following the event with longterm normal 11-13 September conditions, they suggested that contrails may reduce the DTR over their analysis area by at least $1.1 \mathrm{~K}$. The effect, Travis et al. (2002, 2004) conclude, could even be larger, because observations immediately before and after the grounding period already showed negative anomalies from climatological September DTR. Such a strong aviation impact would even exceed the DTR trend that has been observed for the U.S. area over the last $25 \mathrm{yr}$ (Vose et al. 2005, their Fig. 4). While a strong local contrail impact in regions of high air traffic density, along the line argued by Minnis (2005), might be more plausible for DTR than for mean temperature, drawing climatologi- cal conclusions from an observed anomaly over just one 3-day period must be regarded as highly uncertain. Because, moreover, an alternative explanation for the DTR increase after 11 September 2001 has been given by Kalkstein and Balling (2004), the "Travis hypothesis" (i.e., contrails reduce diurnal temperature range) calls for support from an independent method. Applying the climate model ECHAM4 we have the possibility to run simulations for an aviation-free atmosphere as well as for an aviation-affected atmosphere over many decades. This results in a large dataset of an atmosphere without contrails for the required independent check of the hypothesis proposed by Travis et al. (2002). However, we can only interpret this model data with confidence if they reproduce the observed features of DTR and its correlation with cloudiness. We use 40-yr European Centre for Medium-Range Weather Forecasts (ECMWF) Re-Analysis (ERA-40) data for the evaluation of the model-simulated DTR and also for statistical analysis of DTR trends and confidence intervals. We will also discuss DTR results from station data to ensure that ERA-40 data represent actual observations properly.

In section 2 we are going to describe the model, the simulations, and the observational data that have been used to evaluate its results. The DTR results of the simulations with and without aviation and contrails are given in section 3. Section 4 compares the features of DTR variables and its relation to cloudiness in the model and observational data. Section 5 provides a critical discussion of both the Travis hypothesis and our own results, while section 6 summarizes the conclusions of this study.

\section{Model and data}

\section{a. The ECHAM4 climate model}

In this paper we will rely on the same model configuration as used in Marquart et al. (2003) and Ponater et al. (2005) to calculate the radiative forcing and the climate response of contrails, namely, ECHAM4. L39(DLR), as described by Land et al. (1999). It is based on the ECHAM4 climate model (Roeckner et al. 1996) and is extended by a parameterization for lineshaped contrails. This parameterization is based on the thermodynamic theory of contrail formation (see Schumann 1996, and references therein) and simulates contrail coverage, contrail optical properties, and contrail radiative impact, depending on the ambient conditions for each model time step. Aviation density according to some emission inventory is used as a weighting factor to convert the potential contrail coverage into an actual coverage. More details can be found in Ponater et al. 
(2002) and Marquart and Mayer (2002). Note that the contrail radiative forcing is the difference between radiative flux calculations with and without the contrails, including natural clouds in either case. Thus, situations of co-occurring natural and aviation-induced clouds, as well as situations of contrails under otherwise clear-sky conditions, are both possible, which should produce a realistic variability of the contrail radiative forcing and related heating rates both throughout the atmosphere and at the surface. The model can be used for equilibrium climate change simulations in a version including a mixed layer ocean (MLO), as demonstrated by Ponater et al. (2005). The ECHAM4.L39(DLR) version uses spectral T30 horizontal resolution, vertical resolution of about $700 \mathrm{~m}$ at cruising altitudes (Land et al. 1999), and a time step of $30 \mathrm{~min}$. Except for one simulation (see below) twice-daily data are stored in the archive files. The necessary information on maximum and minimum temperature for each archiving interval, cloud and contrail coverage, cloud and contrail radiative forcing, as well as the usual climate model output is available from all simulations discussed hereafter.

\section{b. Simulations}

Our main simulation is the same as that evaluated in Ponater et al. (2005) and it will be referred to herein as CONT-MLO throughout (MLO indicates the inclusion of the mixed layer ocean). It is characterized by an artificially enhanced aviation effect employing an inventory for the year 2050 that is multiplied by a factor 20. We note that this scaling implies that the forcing is about a factor of 30 larger than it would be under unscaled year 2000 conditions (Sausen et al. 2005). The resulting global mean contrail coverage is $3.2 \%$ and the global mean net radiative forcing at the tropopause is $0.19 \mathrm{~W} \mathrm{~m}^{-2}$. The respective values for the United States are $14.6 \%$ and $0.83 \mathrm{~W} \mathrm{~m}^{-2}$. Qualitatively the radiative effect of contrails is similar to that of thin cirrus: The forcing at the tropopause is positive and determines the mean surface temperature response, which is a warming one. The diurnal temperature range, however, must be expected to be forced mainly by the radiative cycle at the earth's surface. As shown in Meerkötter et al. (1999), the contrail net radiative forcing at the surface is negative on a daily average, except for special conditions like weak solar input at wintertime. The representation of the diurnal cycle of contrail forcing in the GCM will be discussed in more detail below.

The artificial enhancement of the contrail coverage was required in Ponater et al. (2005) in order to produce a surface temperature response with a sufficiently high signal-to-noise ratio that can be interpreted rea- sonably in a statistical sense. Likewise, a simulated mean contrail coverage of $0.6 \%$ over the United States in the unscaled experiment (Marquart 2003) could hardly be expected to produce a significant DTR response, when Dai et al. (1999) find a DTR reduction of about $4 \mathrm{~K}$ as a consequence of a $50 \%$ cloud cover enhancement. Beyond these technical arguments we have to note that the contrail parameterization in the model does only account for the line-shaped part of the AIC forcing and, moreover, the simulated contrail optical depth is rather at the lower end when compared with available observations (Ponater et al. 2002; Marquart et al. 2003). Hence, an amplification of the contrail forcing is recommended in any case, because otherwise the model would probably not receive the magnitude of the total AIC forcing in the real world. Minnis et al. (2004) estimate a radiative forcing of around $0.16 \mathrm{~W} \mathrm{~m}^{-2}$ per $1 \%$ cirrus increase for the United States, while analyzing an actual AIC increase over this area of $1.0 \%$ per decade over a 25-yr period between 1971 and 1995. An upper estimate of $0.08 \mathrm{~W} \mathrm{~m}^{-2}$ is given by Sausen et al. (2005) for the global mean AIC forcing. Regarding these numbers, the contrail radiative forcing of $0.19 \mathrm{~W}$ $\mathrm{m}^{-2}$ (see above) in our main contrail impact simulation is near the upper limit of current estimates of AIC forcing. Thus, if an impact of contrails on DTR existed near the magnitude suggested by Travis et al. (2002), and if the model captured the main features of cloudiness and DTR including their interaction, a significant DTR reduction ought to be expected in the simulation including contrail forcing.

In total, five GCM experiments have been performed for this study: Their characteristics are summarized in Table 1. Beyond the basic contrail simulation (CONT-MLO) and the reference simulation (REF), we are going to consider three further model experiments. One of them (CONT-SST) is identical to CONT-MLO with respect to the introduced contrail forcing, but uses a fixed climatological cycle of sea surface temperature (SST). This simulation is intended mainly to reflect the local contrail impact, because possible feedbacks on DTR via the global warming response occurring in CONT-MLO (Ponater et al. 2005) are suppressed here. Another shorter simulation (CONT-SST-2h) uses the same model setup as CONT-SST but employs a shorter archive interval of 2 rather than $12 \mathrm{~h}$. The diurnal radiation cycle is analyzed from this run. Finally, for reasons to be explained later, a special simulation (HIGHMLO) has been run in which the correlation of natural high clouds (rather than contrails) with the DTR can be studied because high cloud parameters, including high cloud radiative forcing (CRF), have been archived in the data output. 
TABLE 1. Overview over the characteristics of the GCM simulations performed for the present paper. All analyzed years were preceded by sufficiently long spinup periods.

\begin{tabular}{lcclc}
\hline \multicolumn{1}{c}{ Simulation } & Analyzed years & Interval storage & Ocean coupling & Aviation emission \\
\hline REF & 40 & $12 \mathrm{~h}$ & Interactive ocean mixed layer & None \\
CONT-MLO & 29 & $12 \mathrm{~h}$ & Interactive ocean mixed layer & Enhanced \\
CONT-SST & 19 & $12 \mathrm{~h}$ & Constant SST & Enhanced \\
HIGH-MLO & 30 & $12 \mathrm{~h}$ & Interactive ocean mixed layer & Enhanced \\
CONT-SST-2h & 3 & $2 \mathrm{~h}$ & Constant SST & Enhanced \\
\hline
\end{tabular}

\section{c. Observational data}

We use both assimilated reanalysis data and station data as an observational counterpart for the model results. For evaluating the simulated DTR on the global scale we will mainly rely on ERA-40, as described by Uppala et al. (2005), which form a largely homogeneous, consistent, and complete set of global meteorological data over $44 \mathrm{yr}$, from September 1958 to August 2002. Variability and trends of monthly mean surface temperature from ERA-40 were compared by Simmons et al. (2004) with station data from the Climate Research Unit (CRU) source with satisfactory results, although that paper did not include an evaluation of the DTR. Because the main reanalysis data are saved only every $6 \mathrm{~h}$ and do not include cloud radiative forcing, we use the forecast mode data from ERA-40, which are available every $3 \mathrm{~h}$. The meteorological data we apply are total cloud cover and high cloud cover, minimum and maximum temperature over a 3-h archiving interval, as well as the cloudy and clear-sky radiative fluxes at the surface and at the top of the atmosphere (TOA) over the accumulated $3 \mathrm{~h}$. To calculate the direct differences, the ERA-40 data are shown here with reduced horizontal resolution, that is, on a grid of approximately $3.75^{\circ}$ latitude $\times 3.75^{\circ}$ longitude, identical with the Gaussian grid associated with the T30 spectral model resolution of ECHAM4.

Despite the above-mentioned merits of the ERA- 40 dataset, for regions and periods with sparse data coverage there is still the possibility that these data are marred by biases of the assimilation model (Simmons et al. 2004), and influences of local surface specifics may be missing because of their comparatively coarse resolution. Moreover, trends may be unfavorably modified by uncorrected data inhomogeneities. Hence, we will include in the evaluating discussion analysis of observed DTR variability and trends from ground station measurements (e.g., Dai et al. 1999; Vose et al. 2005; Dai et al. 2006). The observational dataset of Dai et al. (1999) is based on 30-min-averaged surface data from the First International Satellite Land Surface Climatology Project (ISLSCP) Field Experiment (FIFE) and synoptic weather reports of 1980-91 from about 6500 stations worldwide. The Vose et al. (2005) DTR analyses are derived from the well-documented Global Historical Climatology Network data. Because the sensitivity of climatological DTR trends to local changes like urbanization is not quite clear (e.g., Braganza et al. 2004), we will also show some trend results here that we derived from the CRU station dataset (Mitchell and Jones 2005), which includes such effects. Moreover, unlike the observations given by Dai et al. (1999), this dataset covers the entire twentieth century (1901-2002) and could be evaluated for a longer time period comparable to the ERA-40 period (1958-2001). Another advantage of the CRU station data for large-scale analysis is that they are provided as a fine-resolution gridded dataset (we used CRU-TS 2.1, which has a resolution of $0.5^{\circ} \times 0.5^{\circ}$ ), although it has to be noted that the quality of the data depends on the number of stations available to form a grid cell mean. While this limits the quantitative reliability and comparability of DTR values for individual grid cells (particularly for trends), the qualitative reliability of large-scale structures in regions reasonably covered by station should be retained.

\section{d. DTR calculation}

Maximum and minimum temperatures at stations are provided by the appropriate instruments to account for extremes reached between two measurement dates, and such measurements should also largely determine the respective values in the ERA-40 data given every 3 h. In the GCM, this measurement process is imitated by keeping an account of the maxima and minima simulated for temperature during the time steps forming an archiving interval (usually $12 \mathrm{~h}$, see above). Model DTR is thus calculated from Eq. (1) as

$$
\begin{aligned}
\operatorname{DTR}^{(i)}= & \max \left\{\max \left[T_{j}^{(i)}\right] ; \max \left[T_{k}^{(i)}\right]\right\} \\
& -\min \left\{\min \left[T_{j}^{(i)}\right] ; \min \left[T_{k}^{(i)}\right]\right\},
\end{aligned}
$$

where $i$ refers to the calendar day, while $j$ and $k$ represent the time steps within the first and the second half of the day, respectively. Thus, the first term of the righthand side indicates the absolute temperature maximum; the second term on the right-hand side is the 

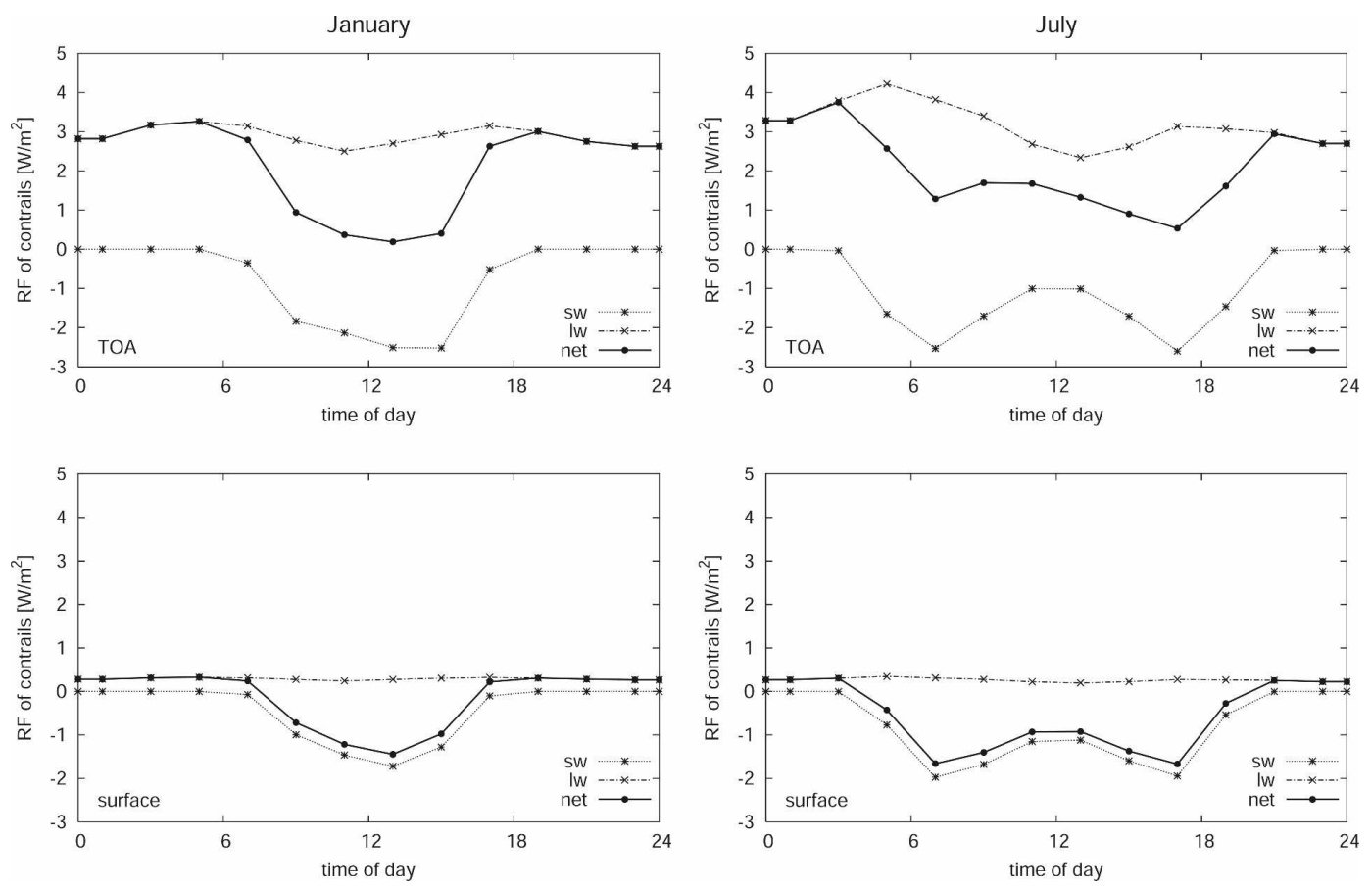

FIG. 1. Mean diurnal cycles of shortwave (sw), longwave (lw), and net (net) radiative forcing from contrails at the TOA and the earth's surface for the months of January and July. Area means over western Europe $\left(39^{\circ}-54^{\circ} \mathrm{N}\right.$, $11^{\circ} \mathrm{W}-19^{\circ} \mathrm{E}$ ) were calculated from a ECHAM4 simulation, the forcing exceeding that of 1992 aviation by an artificial factor of 60 (CONT-SST-2h).

absolute temperature minimum during a 24-h archiving interval. The only problem that arises in the model (as well as in the reanalysis data) is that data are archived at 0000 and 1200 UTC, not at local time. Hence, at most sites it is not possible to attribute either the daytime or the nighttime extreme exactly to one calendar day. Using surface temperature data from CONT-SST-2h, we did an extra check at several grid points where local time has a considerable shift with respect to UTC time, in order to ensure the reliability of the DTR calculation according to Eq. (1). Even at those sites the DTR calculated according to Eq. (1) is a good approximation on a single-day basis. For climatological monthly means the problem is irrelevant in any case.

\section{Contrail forcing and diurnal temperature range in ECHAM4}

We start to investigate the contrail effect on DTR in the climate model in the most straightforward manner, by considering forcing and response in the CONT-MLO simulation. According to Table 1 that means comparing differences between 29 simulation years with contrail forcing and 40 simulation years without contrail forcing. This approach promises a higher statistical significance than the response during the ob- served 3-day period considered by Travis et al. (2002, 2004).

Contrails may potentially impact DTR as expected by Travis et al. $(2002,2004)$; contrails, similar to natural cirrus clouds, warm the surface at night (because thermal infrared radiation is trapped by the contrails in the domain below them), but cool it during the day (because the reflection of solar radiation dominates over the thermal radiative warming). This assumption is consistent with the contrail parameter study presented by Meerkötter et al. (1999). We tested whether the ECHAM4 model fulfils this expectation by an analysis of the CONT-SST-2h simulation. Figure 1 displays the diurnal cycle of shortwave, longwave, and net radiative forcings from contrails at the TOA and at the surface for western Europe $\left(39^{\circ}-54^{\circ} \mathrm{N}, 11^{\circ} \mathrm{W}-19^{\circ} \mathrm{E}\right)$. The January and July figures represent an average over the various conditions (including contrail properties, solar zenith angle, ambient temperature, humidity, and clouds) that may occur for the respective calendar months during the course of the simulation.

For both months, contrails cause negative shortwave and positive longwave radiative forcings at TOA (see Table 2). In July the shortwave forcing of contrails reaches its highest (negative) values in the morning and in the evening hours, when the altitude of the sun is 
TABlE 2. Longwave (lw), shortwave (sw), and net radiative forcing (net) at TOA and the surface (sfc) for January and July conditions $\left(\mathrm{W} \mathrm{m}^{-2}\right)$. The means correspond to the diurnal cycles displayed in Fig. 1 (averages over western Europe).

\begin{tabular}{lcccc}
\hline \hline & January (TOA) & July (TOA) & January (sfc) & July (sfc) \\
\hline Lw & 2.90 & 3.16 & 0.29 & 0.26 \\
Sw & -0.82 & -1.14 & -0.46 & -0.89 \\
Net & 2.08 & 2.02 & -0.17 & -0.63 \\
\hline
\end{tabular}

lowest. Because of generally larger zenith angles during the winter months, the January curve shows a different shape with only one minimum at noon. Similarly to the global annual mean (see section $2 \mathrm{~b}$ ), regional net radiative forcing of contrails at TOA is positive in the diurnal mean because of a high positive contribution from nighttime values. We note that the diurnal cycles in Fig. 1 (TOA) are qualitatively consistent with the corresponding results for the nonscaled contrail simulations (see Marquart 2003, her Fig. 4.1), but because of our scaling the present values are by a factor of roughly 60 larger.

The bottom panels of Fig. 1 show the radiative forcings at the surface. The surface shortwave forcings are also negative with only slightly smaller values than at the TOA. The longwave forcings, however, are strongly reduced in magnitude compared to the TOA values (see Table 2). Thus, the net surface forcing of contrails is negative for the diurnal mean, with a similar difference between daytime cooling and nighttime warming as that found at the TOA. These results qualitatively reproduce the daily cycles of contrail radiative forcing, presented in Meerkötter et al. (1999, their Fig. 4). Their absolute values are somewhat higher than ours, because Meerkötter et al. (1999) assumed a sky fully covered by contrails in an otherwise cloud-free atmosphere.

The diurnal cycle of air traffic, which was shown to modulate the contrail radiative forcing at the TOA significantly (Myhre and Stordal 2001; Stuber et al. 2006), is not represented in our simulations. Because aircraft are flying more frequently during day in most regions, including this effect would enhance the contrail-induced surface radiative loss during day, while reducing the respective radiative gain during night. This would enhance the magnitude of the daily mean net surface forcing by contrails, but with only a small effect on its diurnal cycle. We regard this caveat as very unlikely to cause a relevant effect on the DTR response. Summarizing, the climate model is behaving in line with the basic assumption of Travis et al. (2002, 2004) - that contrails cool the surface during day and warm it during night. In this respect the climate model should be able to reproduce the impact of contrails on DTR. We studied the possible impact of contrails on DTR by comparing the geographical distributions of DTR in the CONT-MLO and REF simulations, but did not find any significant pattern in the response (not shown). Figure 2 shows the probability distributions of daily DTR values sampled over all simulated years for the continental United States $\left(30^{\circ}-50^{\circ} \mathrm{N}, 130^{\circ} \mathrm{E}-50^{\circ} \mathrm{W}\right)$ and western Europe $\left(39^{\circ}-54^{\circ} \mathrm{N}, 11^{\circ} \mathrm{W}-19^{\circ} \mathrm{E}\right)$ in the "Travis month" September. Both regions, which are characterized by a high air traffic density (Marquart et al. 2003), display similar distributions of DTR for both simulations. The U.S.-averaged DTR distributions have means of $9.40 \mathrm{~K}$ for the CONT-MLO and $9.30 \mathrm{~K}$ for the REF simulation, while over western Europe means of $3.73 \mathrm{~K}$ for the CONT-MLO and $3.67 \mathrm{~K}$ for the REF simulation are yielded. Figure 2 indicates that there is no evidence either of a DTR reduction or any other significant contrail impact on DTR for the month of September in the climate model. Other months also show only insignificant differences (which result from random fluctuations of the two climate simulations compared). We recall that the same simulation, CONTMLO, indeed gives a significant area mean temperature increase of $0.2 \mathrm{~K}$ over Europe and $0.25 \mathrm{~K}$ over the United States, as pointed out by Ponater et al. (2005). We considered the possibility that this significant "global warming" in CONT-MLO may mask the direct contrail impact on DTR, because indirect DTR changes in a generally warmer atmosphere are conceivable, for example, because of a change in humidity or natural cloudiness. However, the equivalent simulation with fixed sea surface temperature (CONT-SST), which does not contain a significant global warming, shows no DTR response either. Hence, the climate model response definitely does not support the Travis hypothesis, according to which we would have expected a significant DTR reduction, at least over land areas affected by the main flight routes.

In the following section we investigate the ability of the climate model to reproduce observed variability features of the DTR in order to ensure that the absence of a significant signal is not caused by systematic model errors.

\section{Evaluation of model diurnal temperature range variability}

\section{a. Diurnal temperature range}

We start the evaluation of ECHAM4 results with a comparison of climatological (long-term mean) DTR geographical distributions for the months January and 

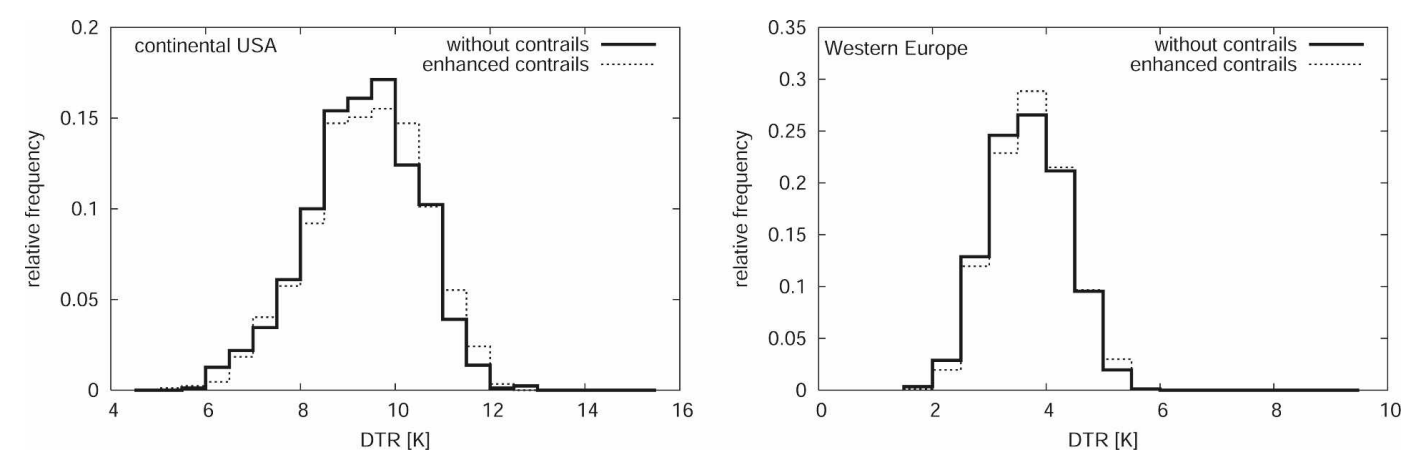

FIG. 2. Probability distributions of DTR over the continental United States $\left(30^{\circ}-50^{\circ} \mathrm{N}, 130^{\circ} \mathrm{E}-50^{\circ} \mathrm{W}\right)$ and over western Europe $\left(39^{\circ}-54^{\circ} \mathrm{N}, 11^{\circ} \mathrm{W}-19^{\circ} \mathrm{E}\right)$ for September, calculated from ECHAM4 simulations with artificially enhanced air traffic (CONT-MLO) and without aviation (REF). Displayed are the relative frequencies for the DTR distributed over 0.5-K classes.

July with respective ERA-40 and observational data. Figure 3 (top panel) shows the geographical distribution of the simulated DTR for the months of January and July. A distinct land-sea contrast appears, with minimal values over the oceans and maximal values over arid land regions, for example, in the subtropics, where evaporation cooling is limited. The small maritime DTR values are due to the high thermal inertia of the ocean. Comparing the modeled DTR in January and July makes seasonal variations apparent. These variations are mainly caused by changes in solar insolation; that is, the reduced insolation in winter is the reason for generally smaller DTR in high- and midlatitude regions. The geographical distribution of DTR calculated from ERA-40 data (Fig. 3, middle panel) shows that the geographical and seasonal variations in DTR are well captured in the model. However the ECHAM4 model underestimates the observed DTR magnitude by $10 \%-50 \%$. To assess whether the ERA-40 data reflect the information gained by actual station observations, we further analyzed the DTR of an observational dataset from weather stations over land (adopted from Dai et al. 1999). Here the DTR monthly mean values range from 4-8 $\mathrm{K}$ over islands and coastal areas up to 12-20 K over inland and arid areas (Fig. 3, bottom panel), exceeding respective values from ERA-40 data (4-6 K for costal areas and 8-14 K inland). The geographical distribution in DTR is again very similar. Differences between station-observed DTR and respective ERA-40 values are likely to be attributable to local conditions at single stations (i.e., vegetation, urban conditions, etc.).

In Fig. 4 we demonstrate the seasonal dependency of the model systematic error by showing the mean annual cycle of DTR over $40 \mathrm{yr}$ for some grid points over selected land areas. The Sahara was selected to represent an arid continental region in the subtropics, and
Wyoming was chosen to represent a region with continental semiarid climate in the United States. The error bars in Fig. 4 denote the standard deviations of the DTR for each calendar day. The site at Wyoming $\left(43^{\circ} \mathrm{N}, 105^{\circ} \mathrm{W}\right)$ has a rather symmetric annual cycle with low model DTR values in winter compared to high DTR values in summer. The site in the Sahara Desert $\left(25^{\circ} \mathrm{N}, 25^{\circ} \mathrm{E}\right)$ displays higher values of model DTR than Wyoming, while the amplitude of the seasonal variation in DTR is smaller as a result of a less distinct insolation annual cycle and more persistent meteorological conditions. For similar reasons, the interannual variability represented by the error bars is smaller there. The mean annual cycles of DTR derived from ERA-40 data also show the underestimation of DTR in the climate model. For Wyoming, the model DTR underestimation is greater in the winter months (about 50\%) than in the summer months (about 10\%). In the Sahara Desert the model DTR is generally underestimated by about $20 \%-30 \%$. However, the annual cycles for both sites have quite similar qualitative characteristics in the ECHAM4 simulations and ERA-40 analyses.

While in most climate models the mean temperature is reproduced close to reality, the underestimation of model DTR has been a common problem. This was demonstrated in several studies, for example, by Kukla et al. (1995), Stone and Weaver (2002), and Zhu et al. (2004). The underestimation of DTR is potentially a result of inadequate parameterizations of the stable atmospheric boundary layer (Holtslag 2006). However, the parameterizations of clouds, radiation, and land surface processes, as well as the absence of a complex topography (Hughes et al. 2007), may also play an important role. An improvement of climate models through considering small-scale processes of the boundary layer and the surface would probably result in a better reproduction of the amplitude of DTR. 


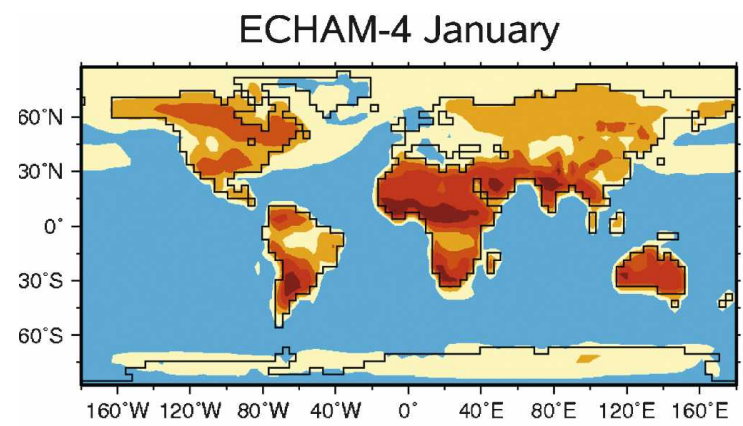

ERA-40 January

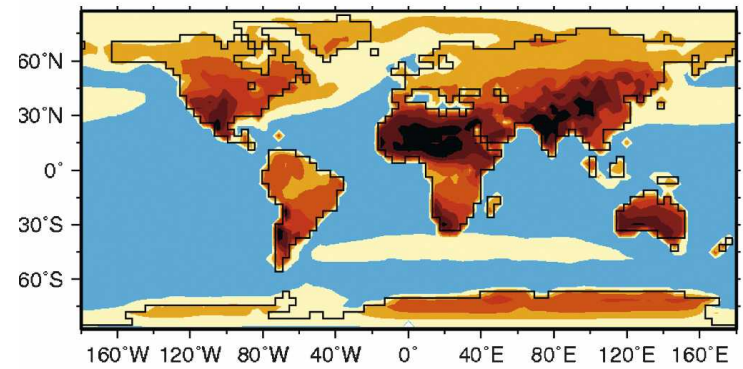

Observations DJF

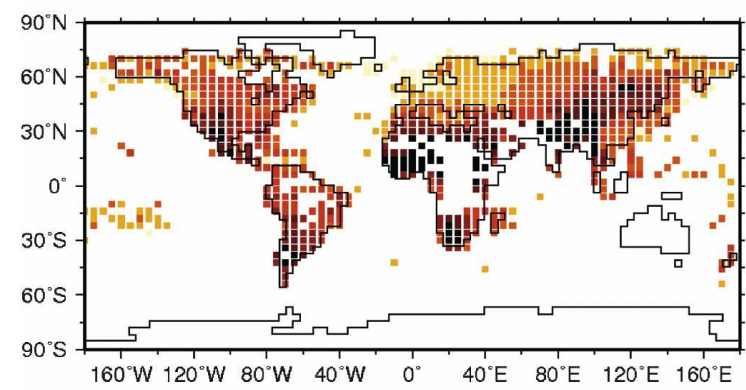

ECHAM-4 July

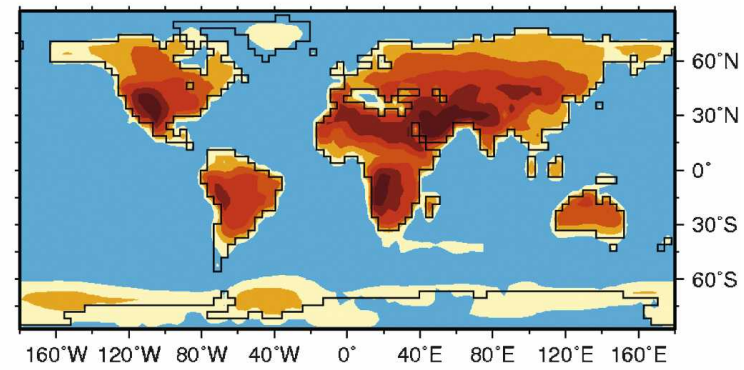

ERA-40 July

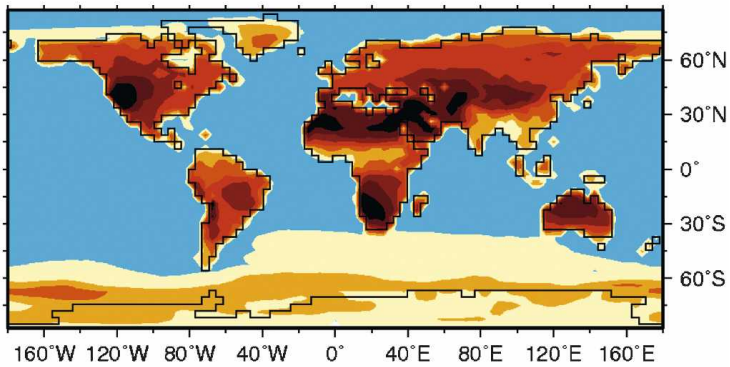

Observations JJA

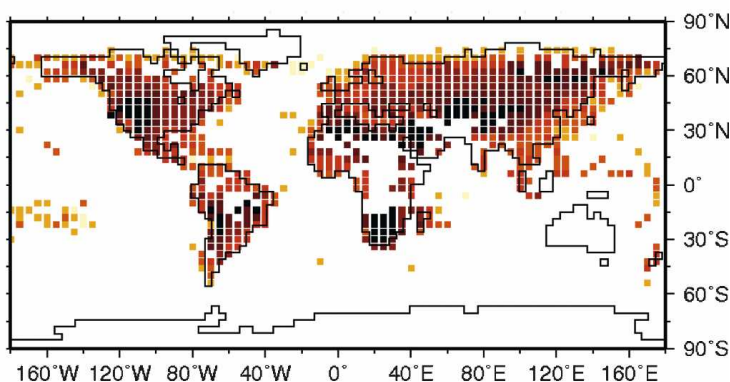

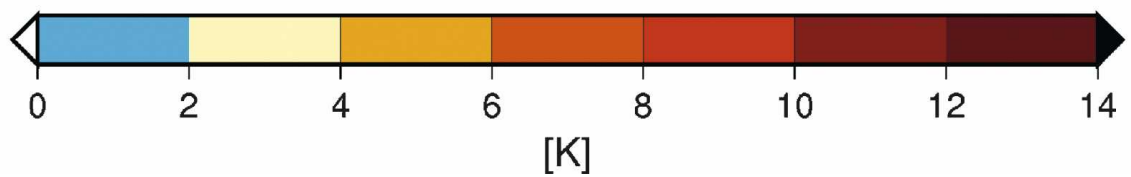

FIG. 3. Geographical distribution of mean DTR from the 40-yr (top) ECHAM4 REF simulation and (middle) ERA-40 data for the months of January and July. (bottom) Mean DTR from station data for winter months December-February (DJF) and summer months June-August (JJA), adopted from Dai et al. (1999).

\section{b. Linear correlation between DTR and cloud coverage}

In this subsection we discuss the correlation between DTR and the total cloud coverage for January and July. Because clouds reduce the surface warming during day (especially when they are optically thick) and reduce surface cooling during night (depending on their emissivity and altitude), a negative correlation (viz., the more clouds, the smaller DTR) is expected and is indeed found when analyzing station data (e.g., Dai et al. 1999). If our model is able to capture this observed correlation it would be worthwhile to use it for an investigation of the Travis hypothesis. Figure 5 depicts the geographical distribution of the corresponding correlation coefficient $\mathrm{R}$ for January and July. As a consequence of the length of our data time series, correlation coefficients with $|\mathrm{R}|<0.1$ are not significant at the $95 \%$ level. For the climate model results DTR and total cloud coverage are negatively correlated in many regions, with maximal (negative) values of $\mathrm{R}$ between -0.8 and -0.6 . Again, the dominant feature is the pronounced land-sea contrast of $\mathrm{R}$, with the highest (negative) values over land. The weak correlation over the 

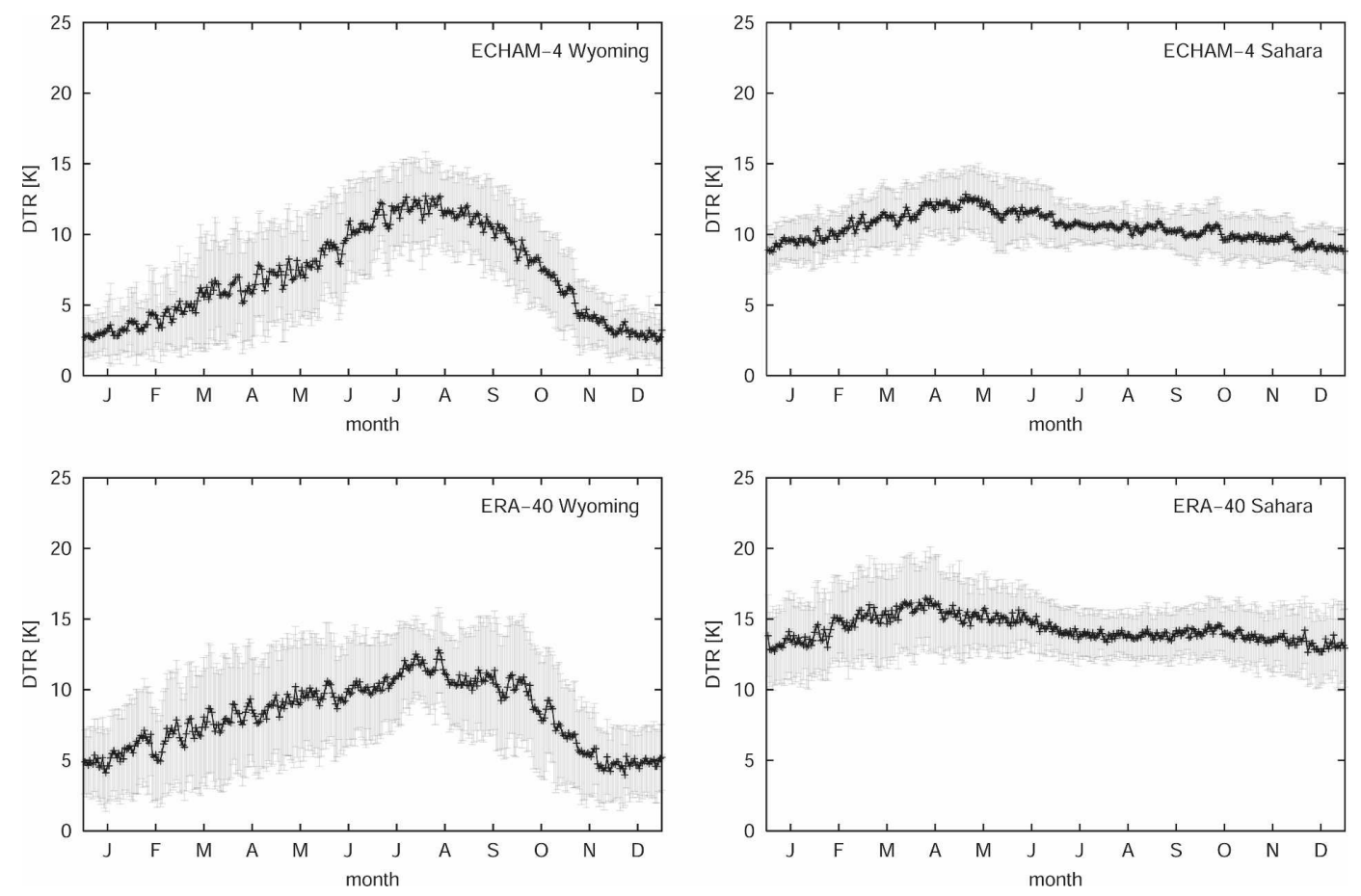

FIG. 4. Mean annual cycles of the DTR for the selected grid points at Wyoming $\left(43^{\circ} \mathrm{N}, 105^{\circ} \mathrm{W}\right)$ and Lybian Sahara $\left(25^{\circ} \mathrm{N}, 25^{\circ} \mathrm{E}\right)$ for the (top) 40 -yr ECHAM4 REF simulation and (bottom) ERA-40 data. The bars denote the interannual standard deviations for each calendar day.

ocean is due to the small day-to-day variations of DTR there. Moreover, the correlation coefficients displays the following seasonal cycle: In the middle and high latitudes of the winter hemisphere, where sunshine duration is short and advection has a stronger influence on the DTR, the correlation is weaker than in the summer hemisphere, where radiation dominates. We also calculated the correlation between the DTR and the CRF at the surface (figure not shown), which are the parameters that are actually linked in a physical sense (see section 3). Here even higher (positive) correlation values with maxima of $\mathrm{R}>0.8$ are apparent. The reason is that in this case clouds at different levels are implicitly distinguished in terms of their specific radiative forcing.

With respect to spatial and seasonal variability, the linear relationship between DTR and clouds in ECHAM4 is in good agreement with the ERA-40 data results (Fig. 5, middle panels). However, slightly larger values of $R$ are found for the ERA-40 data. The significantly positive correlation over the tropical oceans in ERA-40 is surprising and not intuitive. This correlation is potentially not physical, but a consequence of the lack of surface temperature observations over the oceans for cloudy sky conditions in the reanalysis data. In Fig. 5 (lower panel), we reproduce the respective correlation results for observational data from Dai et al. (1999) and find that, qualitatively and quantitatively very similar to ERA-40 data, total cloud cover is negatively correlated with DTR over most land areas. Figure 5 (bottom panel) shows that the correlation is strongest over western Europe, North America, South America, and southern Africa and low over mid- to high latitudes in winter. The only notable disagreement between ERA-40 and station observations occurs over northeast Asia in local winter. The $|\mathrm{R}|$ values of ERA40 data are slightly smaller; for example, the summer correlation coefficients in North America are 0.4-0.8 (July) for ERA-40 data and 0.6-0.8 for the observations (JJA).

Generally, the degree of linear dependence between DTR and natural clouds appears to be described realistically by ECHAM4. This finding suggests that the model should be suitable to investigate a possible relationship between DTR and contrails.

\section{c. Linear correlation between DTR and high cloud coverage}

Cirrus clouds are part of the total cloud cover, but exhibit optical properties and a radiative impact that is distinctly different from low- and midlevel clouds. Contrails show similar properties to (thin) cirrus clouds (Meerkötter et al. 1999). Thus, in the context of this 

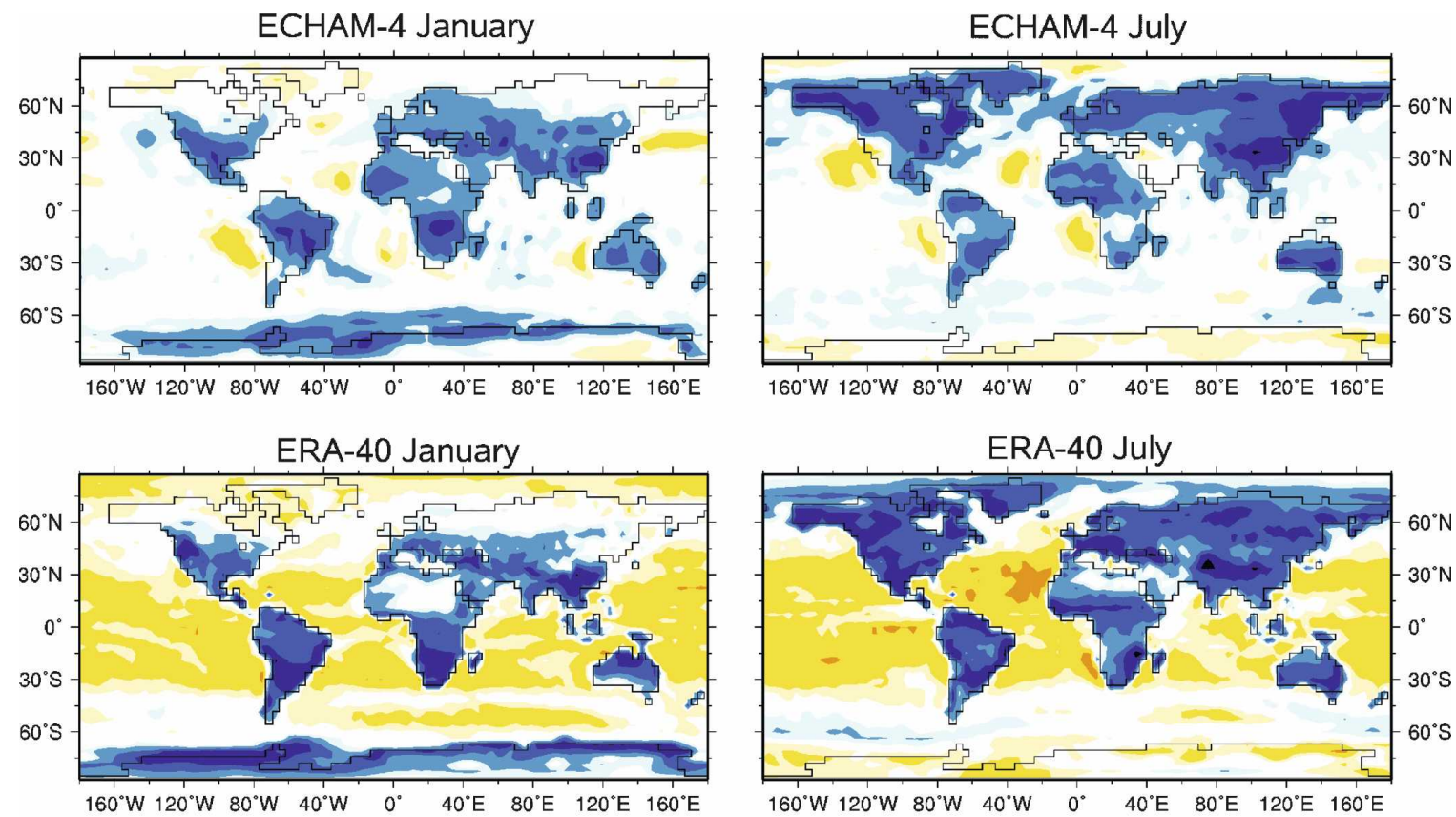

$160^{\circ} \mathrm{W} 120^{\circ} \mathrm{W} \quad 80^{\circ} \mathrm{W} \quad 40^{\circ} \mathrm{W} \quad 0^{\circ} \quad 40^{\circ} \mathrm{E} \quad 80^{\circ} \mathrm{E} \quad 120^{\circ} \mathrm{E} \quad 160^{\circ} \mathrm{E}$
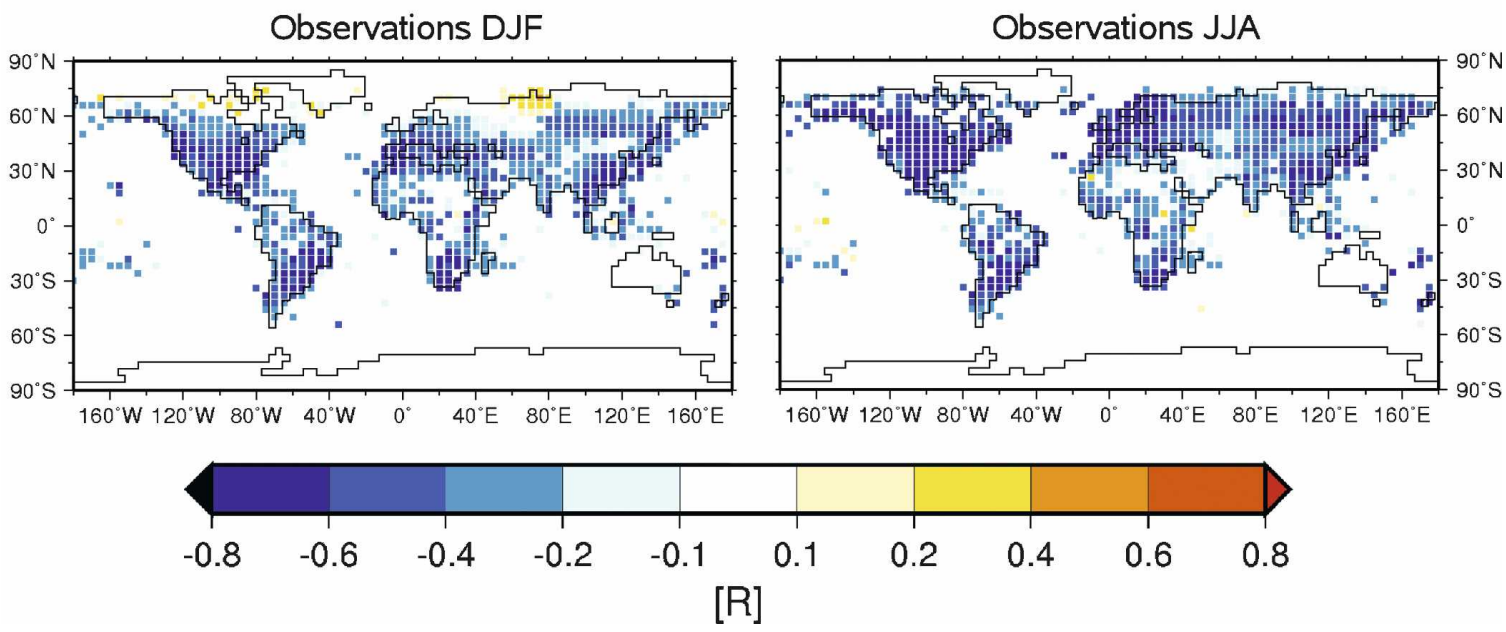

FIG. 5. Geographical distributions of the correlation coefficients R between the DTR and the total cloud cover for the (top) reference simulation with ECHAM4 and (middle) ERA-40 data for the months of January and July. (bottom) Respective correlation coefficients for observational data for winter months DJF and summer months JJA, adopted from Dai et al. (1999).

paper, it is interesting to quantify the linear dependence between DTR and high natural clouds in the same way as for the total coverage. We define high clouds as clouds above $350 \mathrm{hPa}$ with temperatures below the freezing point. Based on data from the ECHAM4 simulation HIGH-MLO, Fig. 6 demonstrates that the correlation between DTR and high clouds is weak in many regions and partly insignificant $(|\mathrm{R}|<0.1)$, especially for local winter. The same correlation analysis for high cloud data from ERA-40 yields a similar behavior for the spatial and seasonal variability (not shown). As in the model, high correla- tion coefficients are restricted to land surfaces in summer, but even here the values remain less than 0.6. There is no high cloud radiative forcing in the ERA-40 dataset, but we introduced a special respective diagnostic into the HIGH-MLO simulation. The correlation between the high cloud radiative impact at the surface and the DTR turns out to be even smaller than between high cloud coverage and DTR, in contrast to what we found for the all-cloud correlation. It is conceivable that in many cases the surface impact of high clouds is masked by underlying low- and midlevel clouds. Generally, physical reasoning is consistent with the finding 

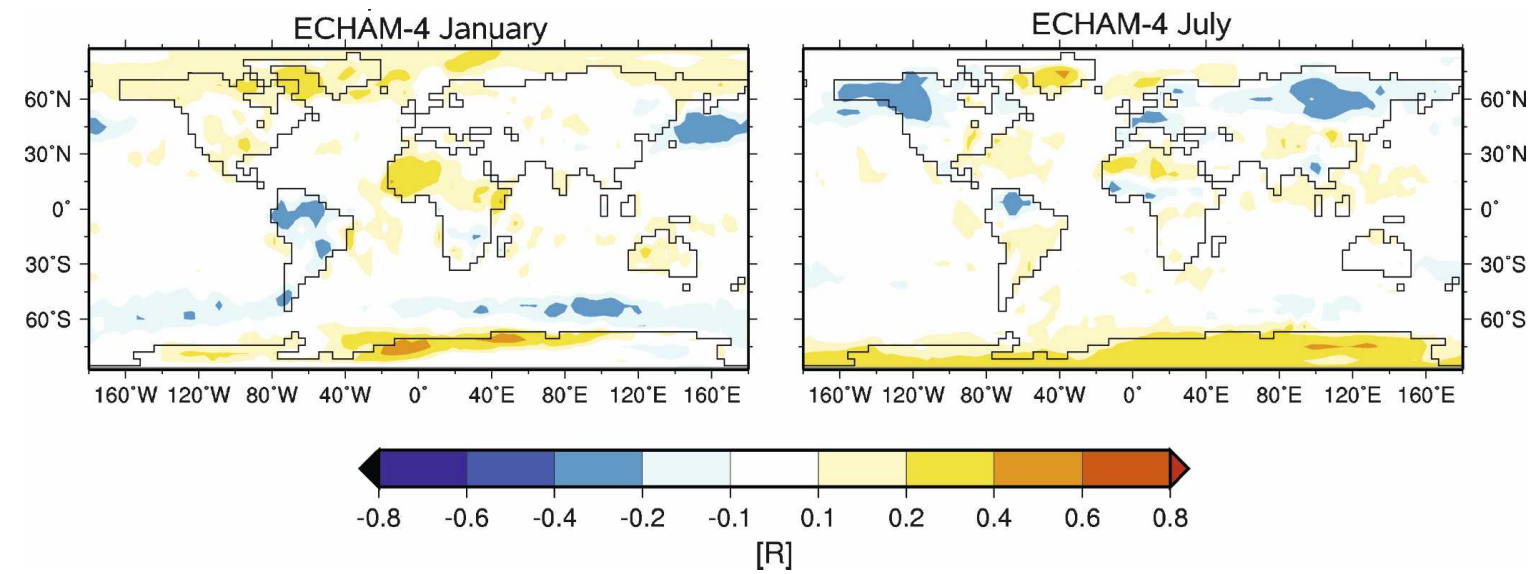

FIG. 6. Geographical distribution of the correlation coefficient R between DTR and high cloud cover for the months January and July. Data are from the HIGH-MLO simulation with ECHAM4.

that DTR is much less correlated with high cloud than with low cloud changes: High clouds imply a weaker mean radiative impact and also a weaker day-night difference of surface radiative forcing. This is also in agreement with the results of Dai et al. (1999), who showed that low clouds mainly contribute to the damping of DTR.

\section{Discussion}

Obviously, the results of the climate model simulations presented in section 3 contradict the Travis hypothesis of a significant contrail impact on DTR. The conflicting results deserve a critical discussion. We take a look at the DTR trends to be obtained from ERA-40 and from station data from the CRU source. Although Travis et al. (2002) do not provide a detailed discussion of trends, it is crucial for the viability of their hypothesis that DTR has decreased over regions with high air traffic during recent decades. Penner et al. (1999) provide evidence that civil aviation between 1970 and 1995 in terms of passenger kilometers has increased by factors of 3.7, 5.2, and 7.5 over inner North America, inner Europe, and Japan, respectively. DTR trends from published station data analysis do not suggest a strong impact of contrails, because they are either insignificant for periods where the largest aviation increase took place over the United States (Dai et al. 2006) or display weak spatial correlation to the aviation density pattern (Vose et al. 2005, their Fig. 4). A DTR trend analysis over the continental United States with the CRU gridded dataset (CRU TS 2.1) results in significant negative trends for July and the Travis month of September (see Fig. 7, top panel). Figure 7 (bottom panel) shows the ERA-40 trend of DTR for the years of 1958-2001 over the continental United States in July and September. CRU- and ERA-40-derived trends agree with respect to sign over the ERA-40 period. In July the total change amounts to about $-1 \mathrm{~K}$ for the years 1958-2001, which is near the value found in the Travis study, while the September trend in ERA-40 is smaller by a factor of 4. For both months the trend is significantly $(p<0.01)$ negative, although the significance in ERA-40 is only marginal for September. Nevertheless, this significant DTR decrease over the United States during the ERA40 period would appear to be consistent, qualitatively, with the Travis hypothesis.

The geographical distribution of the September DTR trend is shown for CRU gridded station data and for ERA-40 data in Fig. 8. A look at the CRU dataset reveals that the largest negative DTR trends (with values more negative than $-0.06 \mathrm{~K} \mathrm{yr}^{-1}$ ) can be noticed in areas over eastern Europe and western Asia, whereas large positive values of DTR trend show up over the southern-central United States, even though the overall DTR trend over the entire continental United States is slightly negative (Fig. 7). ERA-40 data show the largest negative DTR trends over some regions of North and South America, as well as in areas over Europe and Asia, whereas a high positive DTR trend is located near the equator over Africa. Comparing the two datasets, differences in the DTR trend are obvious, particularly over regions with sparse observations. However the large-scale structure is similar over regions with high station density. Although the distinct DTR increase over the central United States in the CRU data is not reproduced by ERA-40, the general spatial structure is still indicated with a weak maximum near $90^{\circ} \mathrm{W}$ surrounded by two minima along the coastal areas. In any case, for both datasets the geographical pattern of DTR 

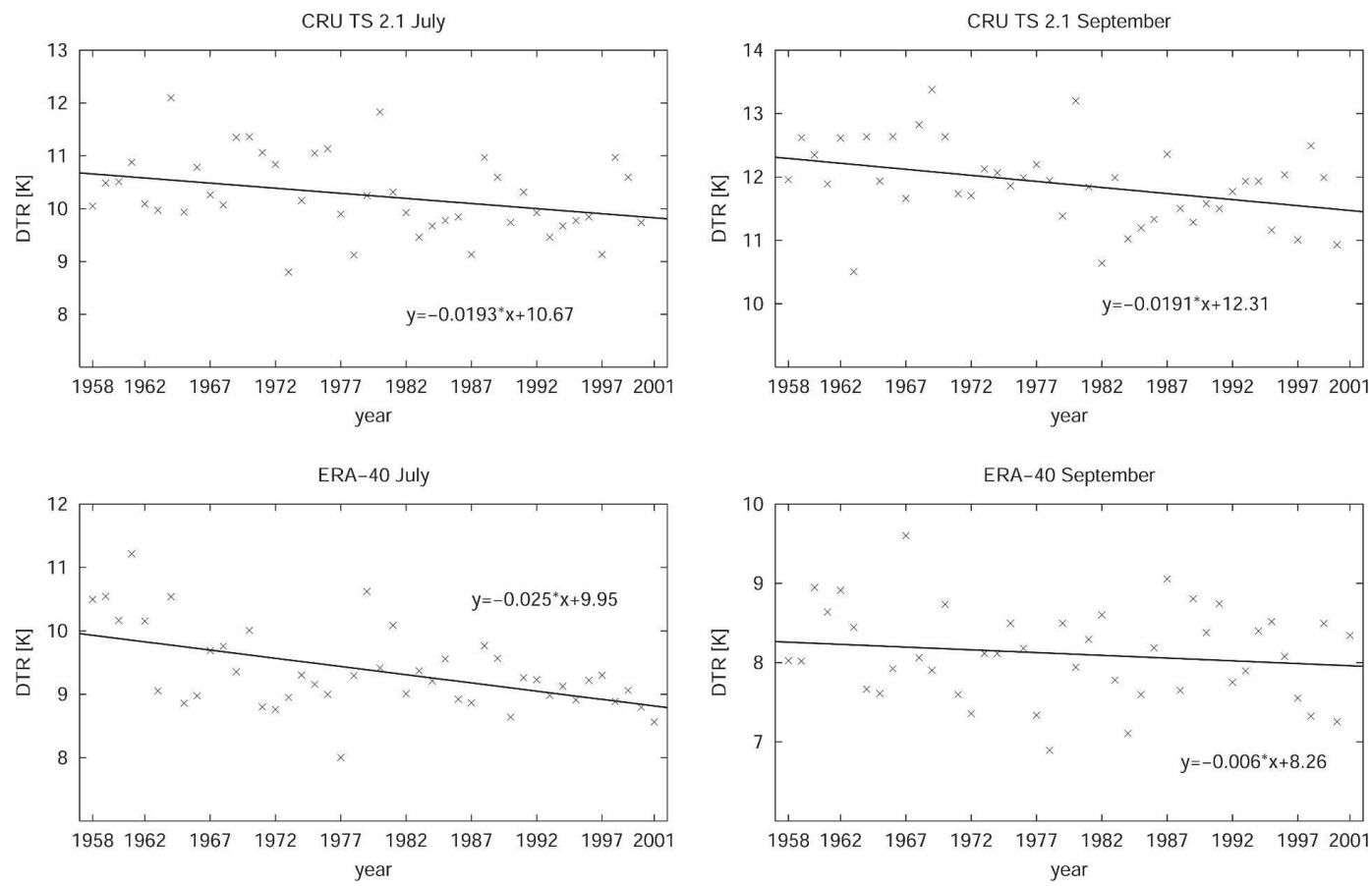

FIG. 7. Trend of monthly mean DTR for the period of $1958-2001$ over the continental United States $\left(30^{\circ}-50^{\circ} \mathrm{N}\right.$, $130^{\circ} \mathrm{E}-50^{\circ} \mathrm{W}$ ), calculated (top) from the gridded station dataset CRU TS 2.1 and (bottom) ERA-40 data.

trends lacks the required correlation with the respective pattern of aviation density and contrail coverage that would allow the overall DTR reduction to be attributed to an aviation increase. Maximum negative values over North America and western Europe expected to be due to aviation are not evident in either data, indicating that negative trends can hardly be explained by contrail coverage. In the DTR trends derived from the CRU TS 2.1 data there is little evidence of any trend between 1980 and 2001, a feature that is also evident if means over the global land surfaces (rather than the United States) are analyzed (Wild et al. 2007). This is suggestive of a global rather than a regional cause for the respective trends.

We note that reasons other than aircraft contrails have indeed been proposed to explain climatological DTR trends such as either cloud cover changes associ-
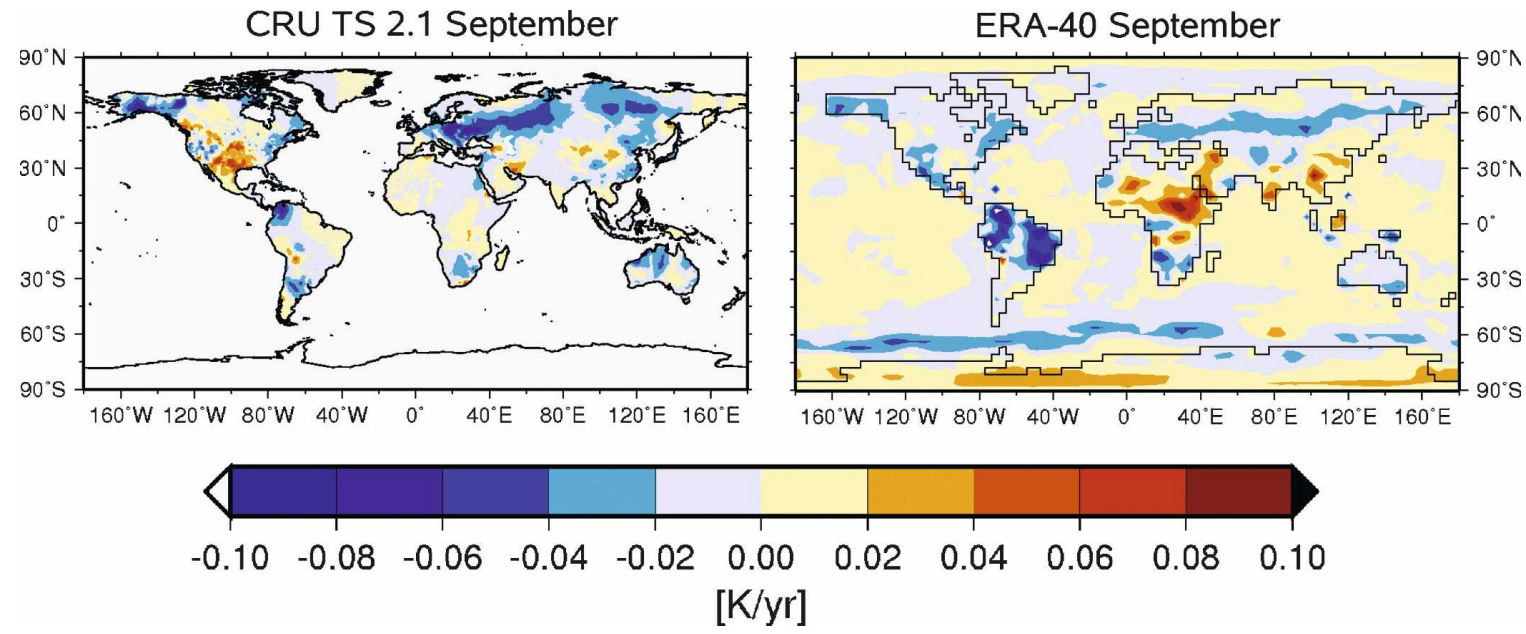

FIG. 8. Geographical distribution of the DTR trend $\left(\mathrm{K} \mathrm{yr}^{-1}\right)$ for September, calculated from (left) the gridded station dataset CRU TS 2.1 and (right) ERA-40 data. 


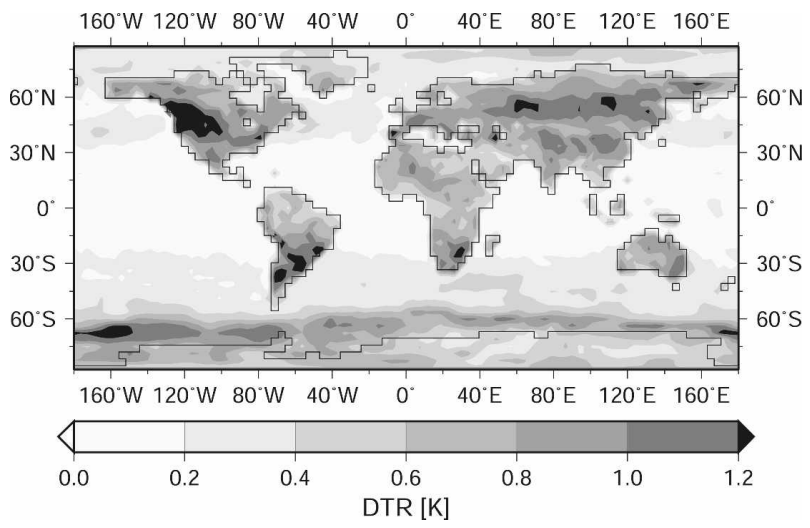

FIG. 9. Geographical distribution of the $99 \%$ confidence intervals for the 3-day period (11-13 Sep) mean DTR, calculated from ERA-40 data for the period of 1971-2001.

ated with global warming (Dai et al. 2001; Stone and Weaver 2002; Vose et al. 2005) or the global dimming of surface solar insolation (e.g., Wild et al. 2007). However, the relationship between DTR and anthropogenic forcings through greenhouse gases and aerosols is complex, because they can affect atmospheric dynamics as well as cloud coverage and optical properties of low clouds (Trenberth et al. 2007).

Reflecting the results discussed so far, there is only weak evidence from either our climate model simulations or reanalysis and station data to support the Travis hypothesis in terms of daily or long-term contrail variability. Kalkstein and Balling (2004) pointed out the possibility of explaining the DTR anomaly analyzed by Travis et al. $(2002,2004)$ in terms of the specific synoptic situation over the United States during the September 2001 period. How significant is a DTR difference of the magnitude found by Travis et al. (2002) compared with the internal DTR variance? We complement our analysis by a calculation of the $99 \%$ confidence intervals of 3-day averages of the DTR for the 1971-2000 period within the ERA-40 data. Figure 9 shows the result for September conditions. Small confidence intervals (minimal values of $<0.2 \mathrm{~K}$ ) can be found over the oceans, especially in the subtropics and tropics, because both the mean DTR (see Fig. 9) and its variability are small because of the thermal inertia of the ocean and stable synoptic conditions. Broader confidence intervals (maximal values of $>0.8 \mathrm{~K}$ ) are located in middle and northern latitudes, where synoptic variability (and, possibly, short-term climate fluctuations as well) has a considerable influence on DTR, as on other variables like temperature, cloud cover, and humidity. This indicates that internal atmospheric variability in midlatitudes on time scales of a few days is associated with DTR fluctuations of similar magnitude as found for the 3-day anomaly by Travis et al. (2002, 2004). A closer inspection of Fig. 9 reveals $99 \%$ confidence interval values between 0.8 and $1.4 \mathrm{~K}$ for the United States. Therefore, deviations from the mean in the order of $1 \mathrm{~K}$, as the deviation of $1.1 \mathrm{~K}$ found by Travis et al. (2002) for the 11-13 September 2001, are similar to the range of natural variability of 3-day means over most areas in the United States. They are at best marginally different from zero in a statistical sense.

\section{Conclusions}

By means of long data time series simulated with a state-of-art climate model we attempted to confirm the hypothesis by Travis et al. $(2002,2004)$ that contrails have a significant impact on the diurnal temperature range (DTR). Although a radiative cooling of contrails during the day and a warming during the night is reproduced by the climate model simulation with enhanced contrails, we could not find any significant decrease in DTR in the multiyear simulations including contrails, even when enhancing the contrail effect to level much higher than expected for 2001 (see section 3 ). The probability distribution of the DTR showed no significant change, even in regions of the strongest aviation. On the other hand, the climate model reproduces the main features of the observed DTR variability as well as its correlation with natural cloud coverage and cloud radiative forcing. An important detail is that the DTR appears to be rather insensitive to high cloud changes in both the model and the ERA-40-observed data (see section 4). This suggests that the impact of contrails on DTR is also small.

We found additional evidence from a decadal trend analysis, which does not support the conclusions of Travis et al. (2002, 2004). The decadal trend of the DTR over the continental United States is indeed qualitatively consistent with the Travis hypothesis, but alternative reasons for such a trend appear to be more plausible, because the geographical distribution of the DTR trend shows little correlation with the main flight routes. Another point questioning the Travis hypothesis is that the decrease in DTR of $1.1 \mathrm{~K}$ for $11-13$ September 2001 lies within the $99 \%$ confidence interval of natural DTR variability, indicating that a 3-day anomaly of the respective magnitude can be largely explained by natural fluctuations. The balance of evidence from our results does not support the proposed large effect of contrails on the diurnal temperature development. The conclusions drawn solely from the climate model simulations would not be fully convincing because of the overall underestimation of DTR. However, the consistency between the climate model results 
and data from ERA-40 is sufficiently distinct to make the attribution of the 1-K DTR anomaly during the September 2001 event to aviation grounding highly questionable. Without new support from observational data during contrail-free periods, the hypothesis offered by Travis et al. (2002) lacks sufficient statistical backing.

Acknowledgments. Parts of this work were funded by DLR/HGF through the project "Particles and Cirrus Clouds" (PAZI-2). The ERA-40 data were kindly provided by ECWMF within the special project entitled "The climatology of the global troposphere." The station data for Figs. 3 and 5 have been provided by Dr. Aiguo Dai from NCAR and were reproduced with his kind permission.

\section{REFERENCES}

Boer, G., and B. Yu, 2003: Climate sensitivity and response. Climate Dyn., 20, 415-429, doi:10.1007/s00382-002-0283-3.

Braganza, K., D. J. Karoly, and J. M. Arblaster, 2004: Diurnal temperature range as an index of global climate change during the twentieth century. Geophys. Res. Lett., 31, L13217, doi:10.1029/2004GL019998.

Dai, A., K. Trenberth, and T. Karl, 1999: Effects of clouds, soil moisture, precipitation, and water vapor on diurnal temperature range. J. Climate, 12, 2451-2473.

—, T. Wigley, B. Boville, J. Kiehl, and L. Buja, 2001: Climates of the twentieth and twenty-first centuries simulated by the NCAR climate system model. J. Climate, 14, 485-519.

—, T. Karl, B. Sun, and K. Trenberth, 2006: Recent trends in cloudiness over the United States. Bull. Amer. Meteor. Soc., 87, 597-606.

Holtslag, B., 2006: GEWEX Atmospheric Boundary-Layer Study (GABLS) on stable boundary layers. Bound.-Layer Meteor., 118, 243-246, doi:10.1007/s10546-005-9008-6.

Hughes, M., A. Hall, and R. Fovell, 2007: Dynamical controls on the dynamical cycle of temperature in complex topography. Climate Dyn., 29, 277-292, doi:10.1007/s00382-007-0239-8.

Kalkstein, A., and R. Balling, 2004: Impact of unusually clear weather on United States daily temperature range following 9/11/2001. Climate Res., 26, 1-4.

Kukla, G., J. Gavin, M. Schlesinger, and T. Karl, 1995: Comparison of observed seasonal temperature maxima, minima and diurnal range in North America with simulations from three global climate models. Atmos. Res., 37, 267-275.

Land, C., M. Ponater, R. Sausen, and E. Roeckner, 1999: The ECHAM4.L39 (DLR) atmosphere GCM: Technical description and model climatology. DLR-Forschungsbericht 1999$31,45 \mathrm{pp}$.

Lobell, D., C. Bonfils, and P. B. Duffy, 2006: Climate change uncertainty for daily minimum and maximum temperatures: A model inter-comparison. Geophys. Res. Lett., 34, L05715, doi:10.1029/2006GL028726.

Mannstein, H., and U. Schumann, 2005: Aircraft induced contrail cirrus over Europe. Meteor. Z., 14, 549-554, doi:10.1127/09412948/2005/0058.

— , and —, 2007: Corrigendum to Mannstein, H., U. Schu- mann, 2005: Aircraft induced contrail cirrus over Europe. Meteor. Z., 16, 131-132.

Marquart, S., 2003: Klimawirkung von Kondensstreifen: Untersuchungen mit einem globalen atmosphärischen Zirkulationsmodell. DLR-Forschungsbericht 2003-16, $161 \mathrm{pp}$.

— , and B. Mayer, 2002: Towards a reliable GCM estimation on contrail radiative forcing. Geophys. Res. Lett., 29, 1179, doi:10.1029/2001GL014075.

— M. Ponater, F. Mager, and R. Sausen, 2003: Future development of contrail cover, optical depth, and radiative forcing: Impacts of increasing air traffic and climate change. J. Climate, 16, 2890-2904.

Meerkötter, R., U. Schumann, D. Doelling, P. Minnis, T. Nakajima, and Y. Tsushima, 1999: Radiative forcing by contrails. Ann. Geophys., 17, 1080-1094.

Meyer, R., H. Mannstein, R. Meerkötter, U. Schumann, and P. Wendling, 2002: Regional radiative forcing by line-shaped contrails derived from satellite data. J. Geophys. Res., 107, 4104, doi:10.1029/2001JD000426.

_, R. Büll, C. Leiter, H. Mannstein, S. Pechtl, T. Oki, and P. Wendling, 2007: Contrail observations over southern and eastern Asia in NOAA/AVHRR data and comparisons to contrail simulations in a GCM. Int. J. Remote Sens., 28, 20492069.

Minnis, P., 2005: Reply. J. Climate, 18, 2783-2784.

—_, U. Schumann, D. Doelling, K. Gierens, and D. Fahey, 1999: Global distribution of contrail radiative forcing. Geophys. Res. Lett., 26, 1853-1856.

- J. Ayers, R. Palikonda, and D. Phan, 2004: Contrails, cirrus trends, and climate. J. Climate, 14, 555-561.

Mitchell, T. D., and P. Jones, 2005: An improved method of constructing a database of monthly climate observations and associated high-resolution grids. Int. J. Climatol., 25, 693-712, doi:10.1002/joc.1181.

Myhre, G., and F. Stordal, 2001: On the tradeoff of the solar and thermal infrared radiative impact of contrails. Geophys. Res. Lett., 28, 3119-3122.

Palikonda, R., P. Minnis, D. P. Duda, and H. Mannstein, 2005: Contrail coverage derived from 2001 AVHRR data over the continental United States of America and surrounding areas. Meteor. Z., 14, 525-536, doi:10.1127/0941-2948/2005/0051.

Penner, J., D. Lister, D. Griggs, D. Dokken, and M. McFarland, 1999: Special Report on Aviation and the Global Atmosphere. Cambridge University Press, 373 pp.

Ponater, M., S. Marquart, and R. Sausen, 2002: Contrails in a comprehensive global climate model: Parameterization and radiative forcing results. J. Geophys. Res., 107, 4164, doi:10.1029/2001JD000429.

,,$-- \ldots$, and U. Schumann, 2005: On contrail climate sensitivity. Geophys. Res. Lett., 32, L10706, doi:10.1029/ 2005GL022580.

Roeckner, E., and Coauthors, 1996: The atmospheric general circulation model ECHAM-4: Model description and simulation of present-day climate. Max-Planck-Institut für Meteorologie Rep. 218, 90 pp.

Sausen, R., and Coauthors, 2005: Aviation radiative forcing in 2000: An update on IPCC (1999). Meteor. Z., 14, 555-561, doi:10.1127/0941-2948/2005/0049.

Schumann, U., 1996: On conditions of contrail formation from aircraft exhaust. Meteor. Z., 5, 4-23.

Shine, K., 2005: Comments on contrails, cirrus trends, and climate. J. Climate, 18, 2781-2782.

Simmons, A., and Coauthors, 2004: Comparison of trends and 
low-frequency variability in CRU, ERA-40, and NCEP/ NCAR analyses of surface air temperature. J. Geophys. Res., 109, D24115, doi:10.1029/2004JD005306.

Stone, D. A., and A. J. Weaver, 2002: Daily maximum and minimum temperature trends in a climate model. Geophys. Res. Lett., 29, 1356, doi:10.1029/2001GL014556.

Stuber, N., and P. Forster, 2007: The impact of diurnal variations of air traffic on contrail radiative forcing. Atmos. Chem. Phys., 7, 3153-3162.

G. Rädel, and K. Shine, 2006: The importance of the diurnal and annual cycle of air traffic for contrail radiative forcing. Nature, 441, 864-867.

Travis, D., A. Carleton, and R. Lauritsen, 2002: Contrails reduce daily temperature range. Nature, 418, 601.

,-- , and,- 2004 : Regional variations in U.S. diurnal temperature range for the 11-14 September 2001 aircraft grounding: Evidence of jet contrail influence on climate. $J$. Climate, 17, 1123-1134.

Trenberth, K., and Coauthors, 2007: Observations: Surface and atmospheric climate change. Climate Change 2007: The Physical Science Basis, S. Solomon et al., Eds., Cambridge University Press, 241-253.

Uppala, S., and Coauthors, 2005: The ERA-40 re-analysis. Quart. J. Roy. Meteor. Soc., 131, 2961-3013, doi:10.1256/qj.04.176.

Vose, R. S., D. R. Easterling, and B. Gleason, 2005: Maximum and minimum temperature trends for the globe: An update through 2004. Geophys. Res. Lett., 32, L23822, doi:10.1029/ 2005GL024379.

Wild, M., A. Ohmura, and K. Makowski, 2007: Impact of global dimming and brightening on global warming. Geophys. Res. Lett., 34, L04702, doi:10.1029/2006GL028031.

Zerefos, C., K. Eleftheratos, D. Balis, P. Zanis, G. Tselioudis, and C. Meleti, 2003: Evidence of impact of aviation on cirrus cloud formation. Atmos. Chem. Phys., 3, 1633-1644.

Zhu, C., D. Pierce, T. Barnett, A. Wood, and D. Lettenmaier, 2004: Evaluation of hydrologically relevant PCM climate variables and large scale variability over the continental U.S. Climatic Change, 62, 45-74. 